\title{
PENGEMBANGAN PROTOTIPE EXECUTIVE DASHBOARD PADA LEMBAGA PENGELOLA DANA CSR (CORPORATE SOCIAL RESPONSIBILITY)
}

\author{
Sudaryono ${ }^{1}$ \\ Joko Dewanto ${ }^{2}$ \\ Arief Herdiansah ${ }^{3}$ \\ ${ }^{1,2}$ Dosen Magister Teknik Informasika STMIK Raharja, \\ ${ }^{3}$ Mahasiswa Magister Teknik Informatika STMIK Raharja.
}

\begin{abstract}
ABSTRAK
Pengembangan prototipe executive dashboard pada lembaga pengelola dana CSR merupakan penelitian yang dilakukan dalam rangka mengimplementasikan sebuah sistem executive dashboard yang dapat membantu manajemen lembaga pengelola dana CSR dalam mengambil keputusan. Penelitian ini dilakukan di CCSR (Cilegon Corporate Social Responsibility). Pada saat ini CCSR belum memiliki sistem dashboard. Pembangunan executive dashboard dibangun berdasarkan model pengembangan dashboard berbasis user centered design dengan menggunakan model prototipe berbasis OOAD (Object-oriented analysis and design). Prototipe diuji dengan menggunakan pengujian ISO 9126. Hasil dari penelitian ini adalah sebuah prototipe executive dashboard arsip digital yang dapat dijadikan sebagai salah satu referensi pimpinan lembaga CSR dalam mengambil keputusan.
\end{abstract}

Kata Kunci: CSR, CCSR, Dashboard, ISO 9126

\section{Pendahuluan}

Dana Corporate Social Responsibility (CSR) merupakan salah satu tanggung jawab sosial yang diberikan sebuah Perusahaan kepada masyarakat sekitarnya. Untuk mensinkronkan dan mengintegrasikan program kerja CSR perusahan dengan Rencana Pembangunan Jangka Menengah Daerah (RPJMD) Kota Cilegon, pada tahun 2011 Pemkot Cilegon membentuk CCSR berdasarkan PerWal Nomor 3 tahun 2011.

Dalam menjalankan program-program CSR, saat ini CCSR menggunakan metode pengelolaan data kegiatan penyaluran dana CSR secara konvensional, hal tersebut dapat menimbulkan permasalahan akurasi rekapitulasi hasil kegiatan dan ketepatan penyusunan rencana kerja penyaluran dana CSR.

Memperhatikan hal tersebut diatas, paper ini bermaksud membahas mengenai pengembangan sebuah sistem komputerisasi pengolahan data kegitan penyaluran dana CSR yang dikelola CCSR yang menghasilkan executive dashboard sehingga dapat membantu manajemen CCSR dalam melakukan pengambilan keputusan ke sektor mana penyaluran dana CSR berikutnya akan dilakukan.

Agar mudah dipahami, penulis membagi paper ini menjadi enam bagian. Pada bagian pertama dimuat penjelasan awal dan urgensi pembangunan prototipe executive dashboard untuk CCSR. Pada bagian kedua dijelaskan metode penelitian yang digunakan. Pada bagian ketiga dijelaskan studi literatur terhadap penelitian yang telah ada sebelumnya terkait dengan executive dashboard. Pada bagian keempat dijelaskan rancangan model prototipe yang dihasilkan. Pada bagian kelima dijelaskan tentang uji 
coba prototipe yang dihasilkan, pembahasan dan diskusi terhadap prototipe executive dashboard yang diusulkan. Pada bagian keenam dijelaskan kesimpulan penelitian.

\section{Metodologi}

Peneliti menggunakan metodologi pengembangan user centered design karena merupakan sebuah metodologi pengembangan dashboard yang didasarkan pada fokus dan efektivitas hasil yang akan dicapai.

Dalam penelitian ini, penulis melakukan tahapan penelitian menggunakan model pengembangan sistem prototipe. Langkah-langkah penelitian melalui beberapa tahapan proses pengerjaan, sebagaimana Gambar 1 berikut ini:

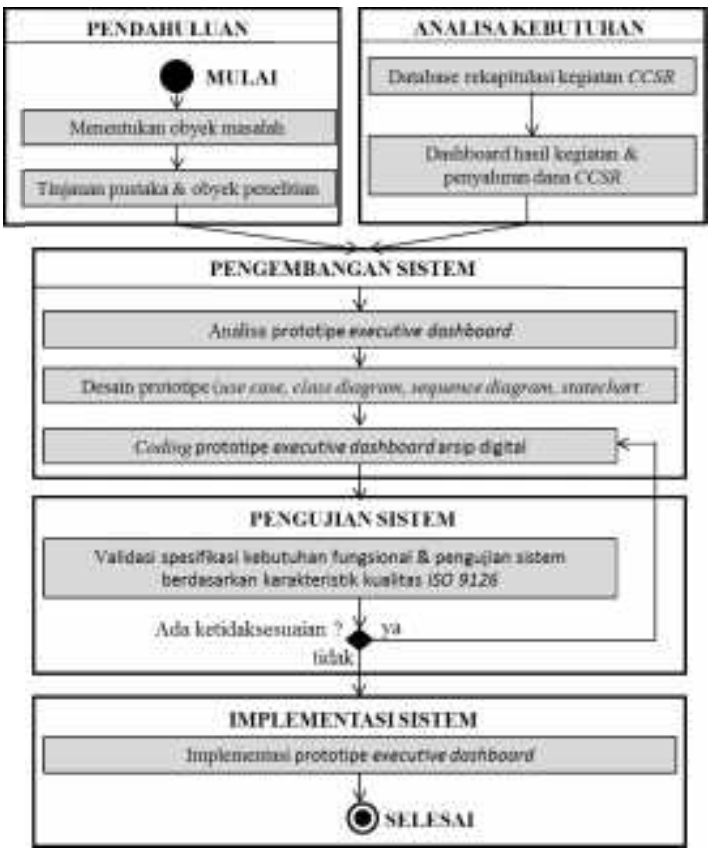

Gambar 1. Langkah-langkah Penelitian

\section{Penelitian Terkait}

Peneliti tentang executive dashboard cukup banyak ditemukan di berbagai publikasi ilmiah, tetapi penelitian tentang executive dashboard pada sebuah lembaga pengelolaan dana CSR belum peneliti temui. Dalam melakukan penelitian ini Penulis mengacu ke beberapa penelitian ilmiah yang berkaitan dengan digital executive dashboard yang telah dilakukan Peneliti sebelumnya, antara lain:

a. Henderi, Suprianti, Ruli [2] tentang Model Sistem Executive Digital Dashboard Untuk Perguruan Tinggi. Tujuan penelitian ini adalah mengolah data yang dihasilkan oleh sebuah perguruan tinggi yang cenderung berlebihan. Hasil penelitian adalah sebuah sistem dashboard dengan software Fusionchart yang disebut EDDU sebagai sebuah visualisasi informasi KPI.

b. Padita, Nugroho, Santosa [3] tentang Model Pengembangan Dashboard Berbasis User Centered Design. Tujuan penelitian ini adalah membahas sejauh mana model Pengembangan Dashboard berbasis User Centered dapat memberikan hasil yang optimal untuk pengguna. Hasil penelitian ini menyimpulkan ada 4 komponen dasar 
yaitu: KPI, hak akses pengguna, basis data, dan desain visual dashboard yang perlu diperhatikan agar dihasilkan sebuah dashboard yang efektif dan jelas.

c. Saryani, Herdiansah, Saputra [4] tentang Digital Dashboard E-Bussiness Pengadaan Material Fabrikasi Pada PT Dharma Eka. Tujuan penelitian ini adalah membuat sistem kontrol material fabrikasi yang dilengkapi dashboard. Hasil penelitian ini adalah sistem dashboard yang mampu menjadi alternatif pemecahan masalah, sesuai dengan kebutuhan perusahaan untuk keberlangsungan produksi.

\section{Rancangan dan Implementasi}

\subsection{Elisitasi Prototipe Executive Dashboard}

Peneliti melakukan elisitasi untuk mendapatkan analisa kebutuhan untuk dijadikan acuan dan dasar penembangan prototipe yang akan dibangun. Hasil dari elisitasi akhir kebutuhan pengguna sebagai berikut:

1. Dari sudut pandang fungsional, pengguna menginginkan sistem yang dapat menampilkan: menu login dan password, menu masukan sesuai model pelaksanaan kegiatan penyaluran dana CSR, menu area/lokasi pelaksanaan, menu Perusahaan yang mendukung kegiatan CSR dan menu dashboard kegiatan CCSR.

2. Dari sudut pandang non fungsional, pengguna menginginkan sistem yang memiliki tampilan framework aplikasi yang menarik, user friendly dan berbasis web

\subsection{Diagram Use Case Prototipe Executive Dashboard}

Diagram use case menggambarkan alur kerja sistem dalam cara yang sangat sederhana, fungsi utama dari sistem dan berbagai jenis pengguna yang akan berinteraksi dengan sistem (Gambar 2).

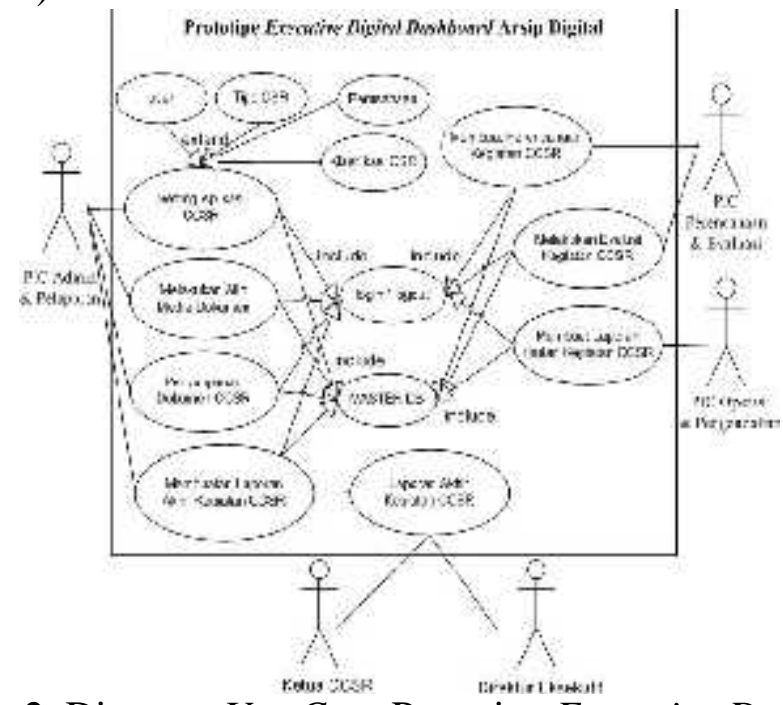

Gambar 2. Diagram Use Case Prototipe Executive Dashboard

\subsection{Diagram Sequence Prototipe Executive Dashboard}

Diagram sequence merupakan model dinamis yang mendukung tampilan dinamis dari sebuah sistem yang dibangun dan dapat berkembang (Gambar 3) 


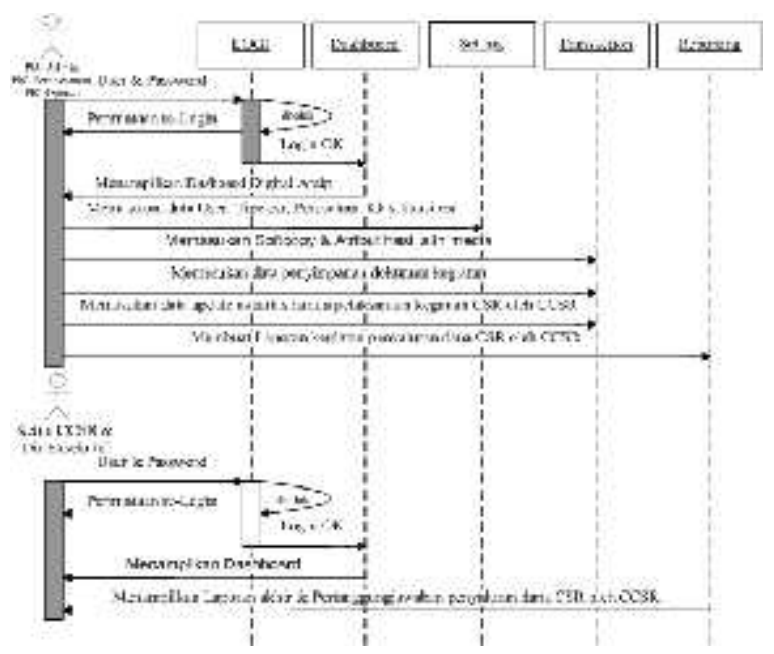

Gambar 3. Diagram Sequence Prototipe Executive Dashboard

\subsection{Hasil Implementasi Prototipe Executive Dashboard}

Pada implementasinya prototipe executive dashboard lembaga CSR dikembangkan menggunakan model pengembangan sistem prototipe, menggunakan Database mySQL dan bahasa pemrograman PHP (Hypertext Preprocessor).

Tahapan pengembangan sistem model prototipe yang peneliti lakukan, meliputi: Quick plan, Modeling Quick Design, Contruction of prototype, Deployment, Delivery \& Feedback dan Communication.

Prototipe executive dashboard lembaga CSR dapat menampilkan informasi berbentuk digital dashboard yang dapat memberikan gambaran umum pencapaian kinerja KPI yang dilakukan oleh CCSR dalam mengeloa dana CSR perusahaanperusahaan di kota Cilegon. Gambar 4a sampai dengan 4c memperlihatkan hasil executive dashboard yang dihasilkan prototipe executive dashboard pada CCSR.

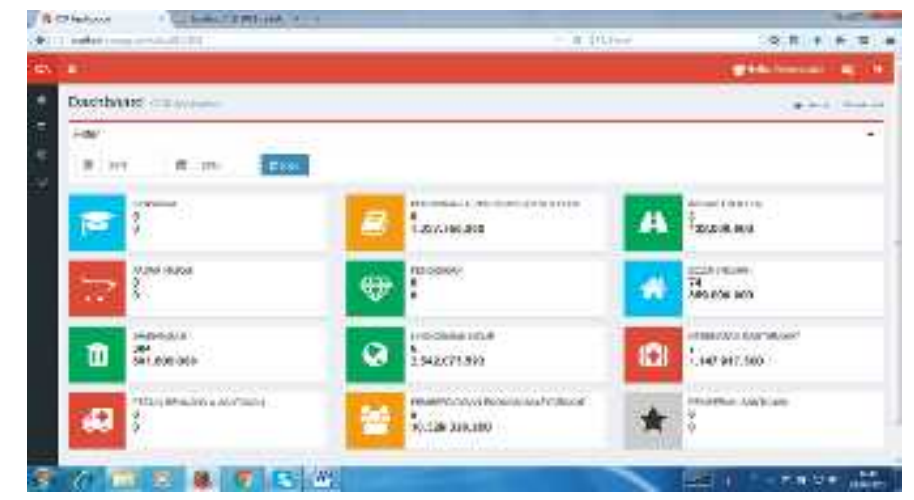

Gambar 4a. Dashboard Penyaluran Dana CSR Per Kegiatan 


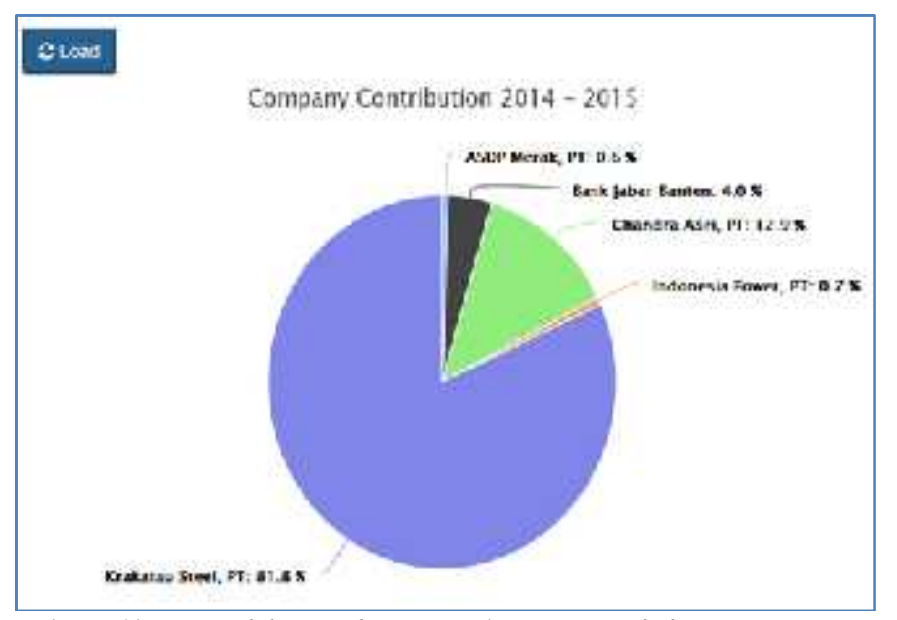

Gambar 4b. Dashboard Perusahaan Partisipan Dana CSR

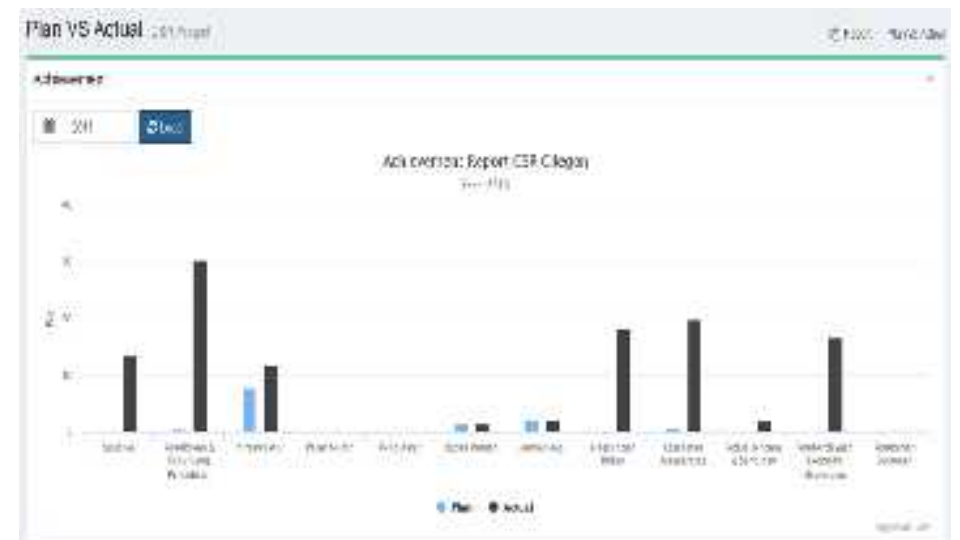

Gambar 4c. Dashboard Perbandingan Target \& Aktual

\section{Pengujian, Diskusi dan Pembahasan}

\subsection{Pengujian Prototipe Executive Dashboard}

Pengujian prototipe menggunakan pengujian kualitas sistem menurut ISO 9126, yang meliputi enam karakteristik pengujian kualitas sebagai berikut:

1. Functionality, sub-karakteristik: Suitability, Accuracy, Security, Interoperability, Compliance.

2. Reliability, sub-karakteristik: Maturity, Fault Tolerance, Recoverability.

3. Usability, sub-karekteristik: Understanbility, Learnability, Operability, Attractiviness.

4. Efficiency, sub-karekteristik: Time Behavior, Resource Behavior.

5. Maintainability, sub-karekteristik: Analyzability, Changeability, Stability, Testability.

6. Portability, sub-karekteristik: Adaptability, Instalability, Coexistence, Replaceability.

Hasil uji prototipe dengan 22 penilaian menghasilkan nilai 95 dari maksimal nilai ideal adalah sebesar 110, sehingga presentase nilai aktual ideal sebesar $=(95 / 110) \times 100 \%$ $=86 \%$, artinya sistem telah memenuhi kebutuhan pengguna dan berfungsi sangat baik. 


\subsection{Diskusi dan Pembahasan Prototipe Executive Dashboard}

Proses analisis prototipe menggunakan metode PIECES untuk membandingkan kelebihan dan kekurang sistem yang berjalan dengan sistem yang kembangkan sehingga dapat dibuat suatu kesimpulan perbaikan. Variabel analisis PIECES ada enam yaitu:

a. Performance (Kinerja)

Prototipe executive dashboard telah mengasilkan sebual prosedur kerja yang lebih efisien tertutama dalam rangka perencanaan dan implementasi CSR oleh CCSR.

b. Information (Informasi)

Prototipe executive dashboard dapat menghasilkan informasi yang jauh lebih cepat dan mudah dimengerti oleh pengguna dan pihak-pihak terkait yang memerlukan informasi berupa executive dashboard dan laporan-laporan kegiatan CSR.

c. Economic (Ekonomi)

Prototipe executive dashboard dapat memberikan manfaat cukup besar yang membuat CCSR dapat melakukan pengelolaan dokumen secara elektronik, sehingga biaya proses distribusi laporan dapat berkurang.

d. Control (Pengendalian)

Prototipe executive dashboard yang dikembangkan memiliki fungsi kontrol baik dari sisi pencapaian KPI CCSR maupun fungsi kontrol operasional dalam rangka menjalankan kegiatan penyaluran dana CSR.

e. Efficency (Efisiensi)

Prototipe executive dashboard yang dikembangkan membuat proses penyampaian informasi dari operasional ke manajemen jauh lebih efisien, sehingga manajemen CCSR dapat dengan cepat dan akurat mendapatkan informasi berkaitan dengan kegiatan penyaluran dana CSR oleh CCSR.

f. Service (Layanan)

Prototipe executive dashboard yang dikembangkan menghasilkan laporan yang terstruktur sehingga membuat CCSR dapat memberikan layanan pelaporan kegiatan penyaluran dana CSR lebih cepat kepada Perusahaan/Korporasi.

\section{Kesimpulan}

Kesimpulan dari penelitian pembangunan prototipe executive dashboard pada lembaga CSR sebagai berikut:

a. Pengembangan prototipe executive dashboard di CCSR dapat berfungsi dengan baik ditunjukkan dengan tersedianya kecepatan dan akurasi informasi yang diperoleh baik dalam bentuk dashboard maupun laporan kegiatan CSR. Infomasi yang dihasilkan dari prototipe dapat digunakan manajemen CCSR sebagai salah satu dasar pengambilan keputusan strategis.

b. Prototipe executive dashboard yang dihasilkan merupakan sistem komputerisasi yang baik, teruji kualitasnya dan dapat memenuhi kebutuhan pengguna, dibuktikan dengan hasil pengujian prototipe berdasarkan ISO 9126 dengan hasil 86\%. 


\section{DAFTAR PUSTAKA}

[1] Chowdhary, Pawan., Palpanas, Themis., Pinel, Florian., Chen, Kwei, Shyh., Wu, Y, Freederic., Model Driven Dashboards for Business Performance Reporting. Jurnal IEEE, DOI: 10.1109/EDOCS.2006.34, 2006.

[2] Henderi., Suharto., Tahapan Pengembangan Digital Dashboard Sebagai Tools Enterprise Performance Monitoring. Seminar Nasional Aplikasi Teknologi Informasi (SNATI), 2013, Yogyakarta, 15 Juni 2013.

[3] Padita, O.B.A., Nugroho, A.H, Santosa,I.P., Model Pengembangan Dashboard Berbasis User Centered Design, SNIK 2015, Semarang, 2015.

[4] Saryani., Herdiansah, Arief., Saputra, Jaya, Yusuf, Muhammad., Digital Dashboard E-Bussiness Pengadaan Material Fabrikasi Pada PT Dharma Eka. Jurnal Senasset, Universitas Serang raya, 2015.

[5] O'Brien, A, James., 2008, Introduction To Information Systems, 12th edition. Dialihbahasakan oleh Fitriasari, Dewi., Kwary, Arnos, Deny., Jakarta, Salemba Empat.

[6] Pressman, S, Roger., 2010, Software Engineering: A Practitioner's Approach, 7th edition. New York, The McGraw-Hill Company.

[7] Rahmatullah, 2011, Kemitraan Antara Pemerintah Kota Cilegon Dengan Perusahaan Di Wilayah Kota Cilegon Dalam Meleksanakan Program CSR Melalui Lembaga CCSR. Tesis. Universitas Indonesia, FISIP, Depok. 